Chapter 27

\title{
The SFIN Innovation System - Reflections on Food Cluster Management
}

\author{
Håkan Jönsson and Hans Knutsson \\ Additional information is available at the end of the chapter \\ http://dx.doi.org/10.5772/53175
}

\section{Introduction}

The Skane Food Innovation Network works to help the food industry innovate, to make the future happen in a way that includes better food, increased competitiveness for the food companies within the region and a stronger culinary profile of the region. This chapter aims at presenting and discussing how a Triple Helix cluster initiative can be managed towards innovation. Skane Food Innovation Network (SFIN) is a triple helix cluster initiative located in the South of Sweden. SFIN represents a new type of innovation system. Government aids to individual corporations are no longer allowed due to EU legislation, which has forced Swedish public innovation funding to alter its form and organization. Today such funding is directed to regional industry clusters instead of individual companies. This has prompted innovation of the Swedish innovation system. SFIN is considered at the front line of this development through its highly developed and consistent triple helix model of innovation (OECD, 2012).

The chapter reflects upon how the innovation system works, both in practice and in theory. In practice, it builds on widespread institutional and industry legitimacy, twelve different networks organized around various nodes in the value system, the interplay between systemic innovation meetings and the formation of pilot projects, and not least, the direct involvement of entrepreneurs, customers and the shared value created in the joint action of the two groups. With a systematic approach - detect, develop and diffuse - to innovation, SFIN has moved towards a new innovation system.

The chapter builds on the idea of "bridging regimes" (Jönsson et al, 2011) and argues that innovation could be considered a collective cognitive process. It involves a case, showing the importance of recruiting intermediators that can bridge the different regimes that are imprinted in the actors and make them involved in realizing innovative solutions. Innovation 
inside an existing organization is particularly described and analyzed (Govindarajan and Trimble, 2010; Kotter, 1985). By innovation itself is meant any process or product that sells and creates new value in a market (Edquist, 2002). In theory, the innovation system may be described as a collective cognitive process. The chapter connects theoretical underpinnings from strategy theory and market theory with models of change, institutionalization and culture. Strategy is discussed as a consistent and long-term set of activities (Porter, 1996) and a clear and understandable modus operandi (Miles and Snow, 1984; Drucker, 1994). The system creates a "liquid environment" and increases the "adjacent possible" (Johnson, 2010), where ideas are detected and further developed in a market, defined as any self-referencing group with certain needs in common (Moore, 1991). Such a market view is consistent with the idea that any innovation established through replication (Christensen et al., 2006) in order to survive. Once the change is made (Kotter, 1996)- the developed new value creation is accepted, widespread and taken for granted, the new solution is institutionalized (Veblen, 1904; Hodgson, 1988; Scott, 1995) and part of a specific culture on one or more levels in society (Schein, 2010). The whole process of innovation is about bridging regimes: it could, in essence, be seen as managing stakeholder perceptions through the three stages of detection, development and diffusion, on the three levels of individual, organization and society.

\subsection{Shaping the shaping of the future food industry}

How do you shape the future? As a matter of fact, you don't have to do anything. It will shape itself around you, with or without your involvement or approval. But if you have an idea of what you want to see in the future, there is a challenge ahead. The Skane Food Innovation Network works to help the food industry innovate, to make the future happen in a way that includes better food, increased competitiveness for the food companies within the region and a stronger culinary profile of the region. This chapter aims at presenting and discussing how a Triple Helix cluster initiative can be managed towards innovation.

This chapter is about regional economic development and innovation is a key concept. It is used in the meaning of any process or product that sells and creates new value in a market (Edquist, 2002). The text revolves around the development of Skane Food Innovation Network (SFIN). In 2003 - winning the competition Vinnväxt - SFIN was boosted by national funding the coming 10 years. The objective was to systematically facilitate innovation in the since long established food cluster in the south of Sweden, also known as Skane. Reading the official program description today, almost ten years later, it is strikingly void of normative guidelines of how to go about creating the innovation system. The purpose of the program, called Regional growth through dynamic innovation systems, is

"to promote sustainable growth in the regions based on international competitive ability, by successively developing or further developing the functioning, dynamics and effectiveness of innovation systems in functional regions at an international level. A prerequisite for the programme is the active participation of players from the business community, research organisations, politics and public administration."

The concept of Triple Helix is mentioned in the original directions. The collaboration between business firms, universities and public sector organisation, innovation will result. 
This view of the innovation process could be interpreted in two opposite ways. On one hand, you could expect innovation as a result of the "adjacent possible" in a "liquid environment" (Johnson, 2010), where the mere coexistence of different individuals gives the future new combinations of ideas, DNA, artefacts or other things. This is what Edquist and Hommen (1999) call the "systems oriented" view on innovation processes. On the other hand, there is a strong contender in the "linear" perspective on innovation. Innovation is unidirectional process, where research and development efforts is initiated by public authorities or private firms, which is expected to produce new technology, which in turn provides new solutions to market needs.

\subsection{Purpose and approach}

The purpose of this chapter is to describe and interpret the development and the dynamics of the way SFIN facilitate innovation.

By innovation is meant any process or product that sells and creates new value in a market (Edquist, 2002). In theory, the model may be understood in terms of strategy as a consistent and long-term set of activities (Porter, 1996) and the need for a clear and understandable modus operandi (Miles and Snow, 1984; Drucker, 1994). The system creates a "liquid environment" and increases the "adjacent possible" (Johnson, 2010). A market is any self-referencing group with certain needs in common (Moore, 1991), in which any innovation has to be established through replication (Christensen, 2006) in order to survive.

A major impediment for innovation tends to be the idea that things should be done the way they always have been done. Innovations therefore often occur in settings where actors with different backgrounds join up with a mutual interest to solve the same problem. However, things can also go terribly wrong if the different backgrounds clash instead of fertilizing each other. Sidney Winter and Richard Nelson (1982) have discussed the importance of studying regimes in order to understand why or why not innovations tend to happen. Winter defines regimes in a sector as a specific set of not only regulative institutions and norms but regimes also regulate codified formal as well as tacit informal habits and routines related to common collective and individual practices and beliefs. These practices and beliefs shape and coordinate actions between various groups, individuals, and organizations in the sector. An important role for organisations working with facilitating innovation may be to work for "bridging regimes", as argued in Jönsson et al, (2011).

We are both active in social sciences, business administration and ethnology. We use our set of models of concepts as "temporary walking sticks [to] aid sense making as we go along" (Ghoshal, 2005). Ghoshal questions the pretense of knowledge, resulting from the idea that social sciences should be formed, tested and verified in the same way as natural science and causal theories are. Thus, our eclectic approach is a start trying to understand and verbalise the shaping of the shaping of the future. The approach is to use an eclectic frame of reference, where different models and concepts in the field of business administration are put together in order to show how concepts of strategy, markets, institutions and culture have human understanding and acceptance in common. 
Our effort could be labelled action research (Lewin, 1946, Rapaport, 1970, Susman and Evered, 1978). Action research is defined by Rapaport (ibid.:499): "Action research aims to contribute both to the practical concerns of people in an immediate problematic situation and to the goals of social science by joint collaboration within a mutually acceptable ethical framework."

The empirical account of the chapter is based on our direct experiences of working inside SFIN since 2004. We both started off leading different projects for a few years. Since 2008 we have been part of the management team of SFIN, each heading a separate large operation. In 2010, the Skåne Regional Council, one of the major stakeholders of SFIN, decided to allocate the initiative Taste of Skane inside SFIN. The assignment is to develop Skane in terms of food experiences - tourism, restaurants, food education, and much more. In 2011, the same organisation gave SFIN the assignment of innovating the hospital meals, starting with the small regional hospital in Trelleborg where a role model is to be presented in early 2014.

So, from an eclectic frame of reference and first hand empirical experiences, this story will serve two general purposes - making sense of cluster management in SFIN and advocating the use of individual and common understanding of the subject of change. Individual come collective understanding, as we aim to show, is at the core of innovation.

\section{Skane Food Innovation Network (SFIN)}

\subsection{The development phases of SFIN}

During most part of the $20^{\text {th }}$ century, the Swedish food market has been protected from international competition. The idea of national self-subsistence used to guide Swedish food policy. International competitiveness was not a major issue, since surplus production was limited. During the last decades, though, the Swedish food industry has been rapidly changing from a sheltered national industry into an industry exposed to strong international competition (Lagnevik 2006). In 2003, VINNOVA, the state agency for innovation and systemsoriented research, launched a regionally oriented program for research, technology and deployment/demonstration (RTD). The aim was to promote upgrading and renewal of local innovation and R\&D capabilities and skill building in certain important growth areas with strong regional profiles. One initiative within the Vinnväxt (Winn-Growth) program was granted to the Skane Food Innovation Network, a triple Helix network formed in Skane, Sweden's "bread basket" with approximately half of the nation's food production and R\&D.

After winning the Vinnväxt competition in 2003, this first period of the "cluster initiative" was research oriented. This "research phase" saw a large share of the funding funnelled into research and $\mathrm{PhD}$ student projects. It was characterised by a linear view of the innovation process. As a triple helix organisation, the reactions from the business part of the stakeholders gradually expressed doubts about how the process should gain their companies. The inherent tension between long-term research and short-term profitability pressures of larger companies needed to be resolved. 
The former CEO of SFIN retired in 2006, and a new one was recruited. From being an anonymous "industry body", SFIN now got a person with a strong background working with one of the most successful and innovative Swedish consumer products in a long time. Around 2007, "the entrepreneurial phase" began. Now there was an increased support of entrepreneurs, seen as innovation synapses. It could be regarded a reflex of large companies' urge for here-and-now innovation. SFIN now changed into a rhythm of making more frequent decisions. Each decision, though, concerned smaller amounts of money. In retrospect, the development could be described as the recognition of the systems view on innovation. The typical decision was about a business plan or project plan, and a subsequent need for financial support for implementing it. This kind of decision-making turned out to be very difficult, sometimes almost ad hoc, and the organisation then was struggling for criteria from which to evaluate the proposals. The result, and the problem, was that an inconsistency emerged, no other logic than stimulating individual entrepreneurs in order to create innovation, new firms and more jobs.

The orientations seen in this first half of the Vinnväxt program are direct reflections of what was evaluated and, hence, expected from SFIN by Vinnova. The new CEO, slightly flabbergasted, turned to the board for directions. None was given. Instead, the board and CEO together began articulating a strategic orientation for SFIN. The approach used was recognised from straightforward strategic planning and the traditional management of business. State a vision, formulate a mission and set goals and strategies in order to fulfil the mission. The process was clarifying the ideas and purposes of SFIN. A new organisation structure was created and still holds sway today.

\subsection{The shape of the SFIN innovation system}

The Skane Food Innovation Network is registered as a non-profit organisation. Its constituents are a number of partners, today about 40, and members, today more than 100 . Partners pay an annual fee of about 4000 euro, whereas members pay 300 euro. Partners qualify for board representation, members do not. The board mirrors the triple helix view - large and small companies, universities, and public authorities are all represented by the eleven board members. The Governor of Skane is chairman of the board.

The board has formulated a so called "VAMS", an acronym for Vision, Business Idea (Swedish: Affärsidé), Objectives (Swedish: Mål) and Strategies.

The vision states that SFIN is shaping the future food industry and meal experiences. The business idea is to offer the best network for cooperation of different competences, stage pilot projects and gain credibility from a concrete track record of innovation. From the high credibility, SFIN sustain and develop its network and receives funding from national and international authorities.

The objectives revolve around maintaining the networks in an inclusive manner, and hence increase the attractiveness and deepen and widen the competence base of the industry. Strategies are concerned with deep understanding of future needs and questions in the industry, creating a clear and attractive offer to participate, attracting people with vision and 
drive, organising meetings between companies, entrepreneurs, universities and industry organisations, focusing commercialisation of innovations, taking the role as the network hub and constantly communicating our work and existence.

The operating core is organised in six different areas, each headed by one person. The areas cover as follows:

- Future Strategy: trend spotting, stakeholder relations, governance issues, finance and funding

- Career: student activities, trainee program, attraction of the food industry

- Entrepreneurship: coaching entrepreneurs in the industry and the adherent support systems

- Public Meals: increasing the status and competence of the public meal sector

- Packaging: develop innovative food packaging, small-scale, local producers etc

- Regional Food and Tourism: develop small-scale food producers, food tourism etc

The CEO and the area managers form a management team, also including the communications manager and one representative each from the two largest public stakeholders and funders, Region Skane and the County Council. The management team meet regularly three hours once a week.

From the different areas, various networks are formed. This model is an offspring from the initial CEO network, created by the new CEO in 2006. These networks are gatherings around specific topics, functions or roles in the system. Currently, 12 different networks meet more or less regularly. Apart from the CEO network, SFIN operates a communications network, a public meal network, a retailers' network, an HR network and seven more networks.

The logic is straightforward. In the networks, different ideas surface. Vital ideas, surviving the initial scrutiny of the network itself, are brought to the management team. The management team discuss the innovation potential of the idea. Today, there is a clear-cut evaluation criteria. The innovation has to be of a systemic character. There has to be a dedicated entrepreneur or coalition ready to test it in a pilot project. Finally, there has to be realistic plans of how the pilot project could reproduce itself, on commercial merits.

In summary, SFIN has over the past three years been compressed into six "business areas", a coherent network structure, a management control model and three distinct activities undertaken in order to create the future food industry and meal experiences: we detect a need or potential for innovation, we develop the solution in pilot projects, and we diffuse them to a wider market. This is the SFIN innovation system. This particular "modus operandi" has produced a wide variety of both short-term projects and long-term signature co-operations. The first one was an industry trainee program in open innovation. Another is the training program for elderly homes, "Meal Pleasure for Elderly". A third example is the retail concept "Locally Produced and Carefully Selected". 
On a deeper level, these different examples represent a maturation and consolidation of the early years of wayward - yet legitimate - experimentation. The strategic planning process undertaken in 2008 apparently missed out on the emotional aspect of change by avoiding making a mission statement. The organisation probably was not ready for it, but now the board and management team increasingly speak in terms of social responsibility, sustainability and social capital. The fourth example of this, and a strong confirmation of the credibility that SFIN has earned over time, is the most recent pilot project situated at the Trelleborg hospital. In the next section, the case of Meal Pleasure at the Trelleborg Hospital, will serve as a more detailed look into the dynamics of the SFIN innovation system.

\section{The case of meal pleasure at the Trelleborg hospital}

\subsection{The background}

In 2009, the public foodservice sector was slowly introduced into the SFIN operations. It was obvious that this was a forgotten part of the Swedish food industry. Half of the industry is foodservice, half is retail and consumer-oriented. Half of the foodservice sector is private restaurants and service sector offerings (gas stations, Seven Elevens and the likes), the other half is public sector meals. The major part is served in schools, hospitals and elderly care. Thus, this forgotten part constitutes one quarter of the entire demand in sales value, even more in terms of number of people being served. It is a rather consistent segment from a supplier's point of view, where public procurement law has streamlined the procurement of food and meal solutions. The guests, though, is a completely different thing. The elderly cannot be segmented by age, nor can school kids or patients in hospitals. This is a very demanding part of the food industry with diverse preferences and, on average, weak buying power.

The public foodservice sector is furthermore signified by a low average educational level, a predominantly female labour force, low pay, low rate of training and education on the job and the use of traditional cooking techniques. The most obvious example is the use of high tech ovens, which in fact are small "computerised food factories". Such an oven is expensive. Still it is often used merely as a traditional oven, a few hours a day, five days a week, due to lack of education and incentive.

One particular problem, unique to the public foodservice sector, is the obligation to follow the public procurement law. One important purpose of the law is to optimise the use of taxpayers money and avoid nepotism. This is done by organised procurement using the competitive forces in a marketplace. This works, unless there is a dysfunctional market. In the Swedish food industry, both the retail and the foodservice market are oligopolistic markets. In the foodservice case, there are two large dominating suppliers. These have been continuously intimidating municipalities and counties by frequent and systematic legal actions and court over-rulings of public procurement processes, a tactic aiming at coercing the public organisations to behave in a certain way (likely as to benefit large-scale suppliers). 
The educational level of the staff and the status of the foodservice operations are related to the problem of public procurement. Increasing occupational status and educational level could make the public foodservice customers more demanding, in that way increasing the innovation pace in the Swedish foodservice industry. That is the hypothesis that motivated SFIN to start working with the public sector.

\subsection{The rationales of the Trelleborg project}

Region Skane, the county council, is responsible for healthcare, transportation, cultural and regional development of Skane. It has offered continuous support of SFIN since the start in 1994. Gradually, the confidence in SFIN has increased. In 2009, with 2012 looming, the need for a new procurement of hospital meals for about two thirds of the healthcare organisation was pressing the politicians. The same year, a hospital food process investigation was initiated. The result was a vision for making Skane a role model in food and meals in Northern Europe by 2025.

It was an ambitious vision and it was necessary to take action. A senior foodservice "celebrity" working for SFIN saw it coming and used her leverage in the political sphere in Region Skane to suggest a pilot project to "walk the talk". Said and done, a pilot project in the small local hospital of Trelleborg; was decided upon. There was an existing kitchen ready to use. "Just dust it off and get it running", we were told.

Apart from starting up a dormant kitchen and start cooking tasty food, the short-term goal was, and still is, to innovate the hospital meal experience and to integrate the meal into the healthcare operation. In other words, we got an opportunity to give the meal a higher status in hospitals. The longer-term goal was set to disseminate the idea, to diffuse the model. This is done in SFIN by way of entrepreneurial incentive. This was decided in the early summer of 2011, just before the holidays. In August that year, the adventure started.

\subsection{The SFIN networks paying off}

SFIN got the assignment from the board of Region Skane, along with funding for two years. This funding covered SFIN expenses for the project, not for investments or employment of staff or other Region Skane-related costs. The line-up from SFIN was possible to achieve as a direct result of the network organisation. Various SFIN projects in the past had made it possible for a rather unique and unorthodox set of project members to form.

The common denominator of this group is a genuine interest in making a difference. Normally, there is an obvious attraction to public funding as "easy money", but these people all work long-term with SFIN on reasonable market-based terms.

Initially, the SFIN manager Knutsson worked as a project owner in SFIN alongside with two experienced and highly respected persons. Together, these three people formed a project core group and started to write a project plan. The project plan was accepted by the responsible politicians in late August 2011. 
The project organisation consisted of a political steering committee, a managing steering committee, a work group and a reference group. SFIN participated in all groups. The rest of the participants varied, but represented either the Region Skane corporate level, the Region Skane business development, the Trelleborg hospital or Regionservice (the facility management part of Region Skane coordinating real estate, food, transportation, laundry, and postal services).

At the time in Region Skane, each hospital manager was responsible for all service operations, including the food process, and the organisation of the healthcare. Regionservice had the role of an in-house service integrator, coordinating the service activities in the entire organization.

There were three distinct stakeholders. The hospital of Trelleborg, Regionservice and SFIN. In this context, SFIN was a fairly unknown organisation of ("self-entitled?", some whispered) experts in the field, who had been given a powerful position in reshaping the hospital foodservice in Trelleborg and, more or less explicitly expected, the rest of the Region Skane hospitals. Adding to that, Regionservice had a rather bad reputation in the hospitals, not meeting expectations. Naturally, Regionservice representatives were suspicious and perhaps - offended by the political decision to invite an innovation organisation from the outside "that no-one ever has heard of". Moreover, the project was running against the clock, as the contract with the external food supplier was to expire 31 August 2012. Regionservice, the coordinator and recipient of the SFIN innovations, had 15 months to go.

\subsection{Colliding regimes - The first year's theme}

The first meeting with a group from Regionservice and the Trelleborg hospital was held before the summer, before there was a project plan written. This was the first step in cooperating. The meeting was marked by confusion. There was no previous relations in the group to rely on. Knutsson, chairing the meeting, had nothing but a generally formulated political decision to hold on to. Focus was naturally put on the "dusting off" the hospital kitchen.

SFIN, represented by an experienced, renowned and respected chef, made an initial sketch of the kitchen layout on the basis of available blueprints. The Regionservice real estate division appointed a project leader to organise the starting up the kitchen. This was a young and inexperienced person, as fresh as they come, who got this assignment as her first project. The tight time schedule and the goal to create something entirely new clashed. Soon it was discovered that the previous check of the building, about one year old, had been rough and, as it showed, insufficient. The original estimation was 11 MSEK. It rapidly grew to speculations of 70 MSEK. The needed capacity was 500 meals per day. Any sound investment calculus became impossible. Thereafter, Regionservice got silent and started its own investigation of the Klippan kitchen without the participation of SFIN.

There was obvious tension between Regionservice and SFIN. The director of support and service functions in Region Skane was contacted and introduced to the need to strengthen the Regionservice commitment to the collaborative nature of the project. A collaboration document was written and acknowledged. But the Regionservice investigation was already 
on its way and the door was not opened to SFIN. At that time, it was also decided by the board of Region Skane that Regionservice should take on the direct responsibility for all support functions. That meant that the hospitals were relieved of the support functions, effective January 1, 2012. This stirred things up in Region Skane and the pilot project did not go unaffected. Regionservice got more powerful and the door to SFIN seemed firmly shut. In late January, the door came ajar, though. Suddenly, the real estate project leader forwarded a number of detailed questions from their kitchen architect and kindly asked that we respond the same day.

In the meantime, two people - one dietician and one gastrome - built a remarkable base of knowledge and learnings about the meals in the Trelleborg hospital. The explicit goal was to observe and analyse the potential and need for change in the meal organisation and the quality of the patient's meal experience. They worked in an exploratory fashion and became more and more independent of the project leader, working increasingly with the kitchen issue and the collaboration between Regionservice and SFIN. The first half of 2012 was a period where the project goals first got under real scrutiny. What does it mean to "innovate the hospital meal experience and to integrate the meal into the healthcare operation"? Frequently the phrase "establish a new norm for hospital food" was used in SFIN. That did not bring light to the more and more blurred question - "What do we have to do?" The pressure increased further from an increasing interest and high expectations of the project. And here we were, fumbling for structure and some guidance. And what about the food, where did that go in this huge project?

A hospital kitchen is an important part of the infrastructure. There is a certain minimum efficient scale, given the choice of building, production methods and technology. In the spring of 2012, there was hardly enough expected volume to guarantee an acceptable cost per meal. The projected daily volumes included 300-350 meals to the hospital and about 150 meals to a new psychiatric unit in Trelleborg (RPC), starting up in 2016. 500 meals per day rendered an unacceptable production cost and the entire credibility of the project was being questioned. In that situation, the municipality of Trelleborg caught the project's interest. In the municipality, there was a commonly known need to invest in new elderly care meal solutions. Contacts were made and a letter of intent was written in the spring. Left with a need to find out ways to share the meal organisation, this was a crucial step that in one blow could double the projected production volume in the kitchen. Also in the late spring of 2012, the political decision was made to invest in total 50,1 MSEK in the Trelleborg kitchen. And the project is delayed by one whole year. With the decision finally at hand, the building process got off to a new start. There was a new building meeting and in that meeting, there was a complete breakdown of communication between SFIN and Regionservice.

The demand and expectations from the hospital, RPC and seven different elderly homes in the town of Trelleborg turned out to be difficult to capture and align. The picture of the total demand was very blurred and the design of the kitchen and logistics turned out to be a bad compromise. A calm and focused foodservice manager in Regionservice now entered the project in order to strengthen the project in the eyes of Regionservice and, in some respect, mediate between SFIN and the real estate project group. In order to get hold of the produc- 
tion model, it became necessary to take a stand on the food issue - do we transport hot or cold food, or both? The decision was made by the experienced chef representing SFIN, in mutual understanding with the foodservice representative from Regionservice, to go with the cold alternative. The decision to work with chilled food was supported by the politicians, and opened up a possibility to solve the problem of supplying food to other hospitals in Skane. If the Trelleborg kitchen was expanded, it could serve so much more than merely the few patients and persons in Trelleborg. This, of course, had ramifications on the building project. But the political negotiations were kept secret. Knutsson was allowed to break the news of going for chilled food in a construction meeting. The impression was that SFIN had surrendered and resorted to the cook/chill method. In the meantime, a plan was outlined for a larger solution, which the politicians initially at first supported. However, one week later there was a $180^{\circ}$ turn, and the old plan was only reconfirmed by the politicians. All of this wheeling and dealing went unmentioned to the real estate project group and it was no wonder that SFIN lost credibility in that group. That wasn't enough. The hospital management in Trelleborg had been completely forgotten in this intense and extremely pressured situation and was not happy.

\subsection{Current state}

As the last steering committee before the summer ended, no decision had been made to reorganise the project. As it happened, the project leader met with the service director/project owner the same morning. Referring the meeting, the project leader got an immediate positive response and the service director offered himself to chair the steering committee and to supervise a revising of the project plan and the project organisation.

So, as the summer is almost gone, the project is now divided into four distinct parts of the project (construction, food, meals, and continuous operations). In this scheme, SFIN has now got an explicit development and innovation responsibility for on one hand the kitchen design and a distinct food strategy, and on the other hand the meal experiences of patients, staff and visitors. The construction part of the project now resides directly under the service director. Articulated goals are now present in each respective part. All in all, order has been reinstated and roles and responsibilities are now much clearer.

In Trelleborg, base groups are formed within each clinic, and the hospital management is engaged in the formulation of the Trelleborg policy of patient meals. In that policy, the integration of hospital meals into the healthcare operation resides. The construction planning is underway, and a new, healthy menu is currently planned.

Of course, it remains to be seen, but by early 2014, SFIN and Regionservice will present a new way of working with food in the hospitals of Region Skane. The meal organisation is revamped, the status of the meals is increasing and the quality of the hospital food is dramatically improved by new production and distribution methods. Moreover, the cost of hospital meals is lower than before and the new kitchen turns the conception of high quality foodservice production upside down. From the rest of the country and from other parts of Europe, people start to benchmark and copy the new norm of hospital food, established by SFIN in tight cooperation with Region Skane. Fingers crossed. 


\subsection{Case study learnings}

This case is a story where we want to show more details of the innovation process. We will dwell somewhat upon the difficulties we have experienced from working side by side, with an established organisation.

The story began with the importance of confronting the basic concept of value creation. Change stemmed from an understanding of (the potential for) value creation, in this case supported by external knowledge and experience, but also a strong political awareness and desire to improve the meals served at the Region Skane hospitals. The staff working in the areas in need of change did not, however, recognise the need to the same extent. This was an important learning in the project. Every organisation is shaped to produce a certain outcome. Ongoing operations create, over time, an inertia and inability to adapt to change. One of the participants in the project, a former foodservice manager, drily summed up the operation in one kitchen by saying "this is like it was 25 years ago when I left it".

This pointed to the need for implementing the wish for change to the staff. The success of an organisation is contextual, every organisation is part of a larger system. The supply chain of the hospital food operation relies on education, procurement, IT cooperation between different occupational groups and so on. To isolate and dissect a single part of a system in order to change only that particular part is doomed - the surrounding system will rein in the deviant.

Innovation is based, the case shows, on every individual's understanding, acceptance and estimation of the value of the "new thing". It was most difficult to convey to large groups of people that we shouldn't talk about just food, we had to take the entire meal into consideration. Hospital staff may have longed for "finally getting better tasting food" but the foodservice organisation had a clear view that "cook/chill food is lousy!". This was the real challenge of innovation, finding the motivation and mutual understanding among the kitchen staff and hospital staff at one hand, and the external innovation facilitating actors at the other. We needed to initiate and encourage change agents in a long-term process of changing attitudes and conceptions of how the meals in hospitals are valued and, hence, organised.

We tried to derive changing attitudes, values and conceptions to individuals influencing individuals. The case reveals the importance of tasting sessions, to organise "base groups" at every single clinic and to align top management support, middle management involvement and floor management dedication.

In essence, this is an argument for treating the innovation process as a cognitive process rather than the physical implementation of new work routines. The innovation in this case is the reconceptualisation of a hospital meal. 


\section{Innovation in the light of strategy, markets and institutions}

Looking at the Trelleborg case from a strategic point of view may give further insight on how actions can be planned in order to succeed in innovation facilitation. First of all, the way that SFIN runs its course follows the strategic planning paradigm. But, just to conceptualise a management system in terms of a list of words will not suffice. From theory we can deduce a certain frame of reference, guiding both sense-making and action-taking. The argument is the following:

- strategy is about understanding how you create value to a customer

- the flipside of a good strategy is inertia and a compromised ability to adapt to change

- success is contextual, every organisation is part of a larger system

- innovation is based on every individual's understanding, acceptance and estimation of the value of the new thing

- individuals are influenced by other individuals;

- innovation, defined as "any process or product that sells and creates new value in a market" (Edquist, 2002) is built on a collective cognitive process;

- The SFIN innovation system is built around a systems view on innovation and concerns the management of cognitive processes triggered by the meeting between people.

\subsection{Innovation and strategy}

Strategy has an everyday connotation as a plan. It is implicitly rational, built on analysis and take its form as an ex ante decision to make something special to happen. There is a wide literature on the concept of strategy, but a convergence could be discerned from a number of scholars in the past. In 1975, the Swedish scholar Richard Normann (1975) defined the way a company could dominate competitors, i.e. strategy, as an interplay between the organisation, its products and its markets. Strategy, Mintzberg (1978) has defined as "a pattern in a stream of decisions". A continuation of that definition is recognised in Miles and Snow (1984) and Porter (1996), who define strategy as a matter of activity fit. What counts is what you do, in total.

Miles and Snow (ibid.) present fit in terms of integration of an organisation's strategy, structure and management processes. Misfit breaks down an organisation, whereas tight fit is "the underlying causal dynamic producing sustained, excellent performance and a strong corporate culture" (1984:10). Early fit is the discovery and articulation of new patterns of strategy, structure and process and fragile fit signals vulnerability to change. Tight fit, thus, is the objective for adaptation. Tight fit is built upon

- discovery and establishment of a seemingly easy way to work together towards a chosen goal,

- simplicity and increased understanding by incumbents 
- reduced need for elaborate coordinating mechanisms, creating slack resources to be re-allocated.

- the causal association between the way to work and achieved performance.

Miles and Snow combine the classic thoughts of Selznick (1957) with similar ideas of Normann $(1975,2001)$ and Porter $(1980,1985,1996)$. The easy way to work, well understood by incumbents, could be regarded as a distinctive competence (Selznick, ibid.) and an interplay between the mental models of people, institutionalised organisational behaviour and the way a company runs its business. Normann (2001) indicates that a "business landscape", i.e. an industry structure and its prevailing business logic, could be a result of the "mental maps" of people. Drucker (1994) calls the same thing "the theory of the business". A later heir of these ideas is Jim Collins (Collins, 2001, Collins and Hansen, 2011), who in a massive empirical material derives an explanation of the success of certain companies. It is from disciplined people, thoughts and actions superior performance stems. In the healthcare organization of Region Skane, this is expressed in distinct occupational roles and a strong hierarchical organization. Even though people have to eat, and our wellbeing depends very much on what we eat, people in the medical profession seldom considers how the patient's eating affects its recovery. The "mental map" of healthcare needs to be redrawn.

\subsection{Strategy, inertia and the difficulty of surprise}

When, in SFIN, we speak about getting the unexpected to happen, there is one problem with innovation and strategy. Strategy is a matter of pattern, routines and familiarity. March (1991), among many others, is preoccupied with the choice a firm has to make between exploiting "old certainties" and exploring new possibilities: "The essence of exploitation is the refinement and extension of existing competences, technologies, and paradigms. Its returns are positive, proximate, and predictable. The essence of exploration is experimentation with new alternatives. Its returns are uncertain, distant, and often negative. Thus, the distance in time and space between the locus of learning and the locus for the realization of returns is generally greater in the case of exploration than in the case of exploitation, as is the uncertainty." (1991:85)

This frames the challenge of SFIN and other innovation organisations: how do you help an organisation close the gap in time and space, i.e. between innovation experiments and profitable growth of business? The wider the gap, the less interested an organisation is to bet on something other than the proven way. Christensen (1997) distinguish between disruptive and sustaining innovation, where sustaining innovation is an incremental development of the existing products or methods. Disruptive innovation changes the game, for the customer or the organisation or both. Digging further down the theoretical underpinnings of innovation, Argyris and Schon (1978) introduced the idea of single and double loop learning to a wider public. Learning in a single loop is to learn to do better what you already do. Doubleloop learning occurs when you question why you are doing what you do in the first place you test the assumptions, values and policies underlying the particular action. 
So, the sustaining innovation is a matter of improvement of the existing solution to a problem. You run your thoughts through a single loop - how can we do this better? The degree of surprise by the unexpected is limited. Disruptive innovation, though, is by definition something other than the existing thing. Then, when you enter a "going concern", the accountant's label on an organisation expected to live long, and you should get the unexpected to happen, you could expect resistance.

In more practical terms, Govindarajan and Trimble (2010) differentiate between the main organisation, what they call the "performance engine", and the innovation organisation, the "dedicated team". In order to succeed with exploration, call it innovation, the dedicated team has to work alongside with the people in the performance engine. A partnership has to be established between the exploring and exploiting parts of the organisation.

The main issue, Govindarajan and Trimble argue, is the work relationships among the participating members and decision-makers. Work relationships are analysed in terms of depth, power balance and operating rhythm. Deep relationships are defined as a continuous and tight relationship where two or more people work together with a specific problem. Power balance is a matter of influence and having the final say. It doesn't rely on individual personal authority, but rather the primacy of certain organisational functions over other. Last, the operating rhythm concerns the pace and intervals in which the cooperating organisations work - if one part work in a monthly budgetary cycle and the other in a three-year development process, the operating rhythm will cause the work relation to wither.

What Govindarajan and Trimble teach us in SFIN is, at the very least, that as soon as we enter an existing organisation with an innovation mission, we must take good care of the work relationships we establish. Infrequent, casual meetings with imbalanced power distribution - one way or the other - and differing time horizons, we are by and large bound to fail to innovate. If we don't get to understand each other, the existing view of reality will prevail. In order to redraw the mental maps of the hospital staff to include the hospital meals as an integrated part of the healthcare, we need to get our "partners" in the "performance engine" Regionservice and the Trelleborg hospital to take the patient meals in a double loop - why do we serve meals in the first place? We have to do this in close work relations, where we need to engage deeply in the realities of kitchen staff and healthcare staff, so that we can better understand how people think about and value the work they do. The change doesn't start from our standpoint, it starts from theirs.

\subsection{Innovation, markets and other institutions}

The problem of innovating inside an existing organisation could be further discussed in terms of diversity and interdependence in the organisation (Kotter, 1985). Kotter claims that the larger the organisation, the harder it is to run it efficiently. If we look closer to his explanation, again work relations between people is the object of interest. His argument goes that a smaller organisation, with a narrow scope of technology, products and markets, creates less confusion and disputes than in larger organisation. The larger organisation depends on many people working together, so when interests divert among these interdependent individuals, the organisation gets stiff and bureaucratic. Kotter ponders: "it 
is not by chance that the economist's traditional model of a firm, where only 'rational' economic decision making occurred, and where power struggles and politics were nonexistent, was a small and technologically simple organization that operated in an environment without large customers, suppliers, unions, or governmental regulators, and that employed a relatively homogeneous labor force in a simple organization structure." (Kotter, $1985^{1}$ ). Thus, as soon as the organisation grows, the diversity and interdependence in existing relations have to be managed and led.

Max de Pree in his book "Leadership is an art" (1987) made a classic statement about leading an organisation - "the first responsibility of a leader is to define reality. The last is to say thank you. In between, the leader is a servant." In case of an organisation needing to change, the leader has to spell it out. Kotter (1996) has designed an eight-step model of change, claiming the need to explain, motivate and sustain the change. The now and here must be described, but also the then and there: where are we and where are we going. A small core of people, the "guiding coalition", has the initiative, but in order to succeed, more and more people have to be involved. One important motivator for others to engage is "short-term wins", necessary to underscore the meaning of and reward from participating. Kotter ends his list with the need to persevere and to gradually institutionalise the changes. New behaviour has to be established. If we choose to define "institution" as a pattern of routinized behaviour (Veblen, 1904, Hodgson, 1988, Scott, 1995, Cohen et al, 2004), the links between individual understanding, actions and innovation are again in focus. When changes are institutionalised, the diversity of action and interdependences are not considered.

Yet, the diffusion of certain behaviour is not automatic. Once the leader has pointed out the way, "defined the reality", people need to follow. Think about this definition of a market. A market is i) a set of actual or potential customers, ii) for a given set of products or services, iii) who have a common set of needs or wants, and iv) who reference each other when making a buying decision (Moore, 1991). There is a direct link between Kotter's (1996) eight-step change model and this view of a market. First, there has to be a need for the new thing. Then a group has to advocate the new thing and persuade others to buy it. Transferred to the concept of innovation, defined as "any process or product that sells and creates new value in a market" (Edquist, 2002), it is deeply dependent on a cognitive process where an idea roots itself and grow stronger as more and more people see it and value it. A successful innovation has gained a critical mass of buyers. A product offered by a company creates value to its buyer, otherwise there will be no repeat buying, nor any persuading elaborations to other potential buyers about the good qualities of the product.

The group that formulates the Trelleborg policy for patients' meals sets the stage for the base groups, which are now being formed and activated in the hospital. The base group activity is a conscious move to have the people reflect upon what they do and to discuss it with each other. In that way, under the supervision of the project members, there is a clear "guiding coalition" creating a sense of urgency. From this, the base group activities reduce

1 Here is an example of how innovations challenge existing norms. The Kotter book Power and Influence was read on an iPad, the new way of reading. In there, the pages are dynamically paginated. The traditional way to refer to a quote hence needs a paper copy - the old way is supported by norms and standards. 
the diversity of the staff's different conceptions of a hospital meal. This is the first ripple across the mental map of hospital food being redrawn.

\section{Bridging regimes to boost innovation}

The distance between the concepts of market, institution and culture could be seen as great. However, if we take the above definitions as our viewpoint and listen to Schein (2010) and his definition of group culture, the close relation between the three appears clearly and interestingly. The culture of a group Schein defines as "a pattern of shared basic assumptions learned by a group as it solved its problems of external adaptation and internal integration, which has worked well enough to be considered valid and, therefore, to be taught to new members as the correct way to perceive, think, and feel in relation to those problems." (2010:36). In the western business community, there is an adage that "culture eats strategy". This means that no matter what strategy companies formulate, the implementation will be determined by the culture of the organisation. Culture is based on past experiences, what has been working. Strategy, defined as a plan, is about future competition and profits. Culture is based on inductive emotional consequence, strategy is based on deductive rational choice. The statement could be tested on other cultural levels than the organisation.

Culture, Schein (ibid.) suggests, could observed on a macro level (national, ethnic), organisational level (private, public, nonprofit, government), on a sub level (occupational) and on a micro level (units, teams, groups within a larger organisation). Thus, if we extend the argument of culture eating strategy, it becomes imperative to take existing cultures into account if enduring change is wanted. In that sense, there is wind in our sails now, as the Swedish healthcare establishment increasingly directs attention to deteriorating hospital food. However, the real challenge of re-conceptualizing the hospital meals is found at the occupational and work group levels. These cultures need to be confronted and overtly discussed if they are to be altered. And to the extent they are, the innovation project will succeed.

Following Levinthal (1991) and Scott (1995) regimes have three dimensions: i) cognitive rules, related to belief systems, ii) normative rules expressed in missions, goals, and identity, and iii) strategies and strategic orientations towards the surrounding external socio- technical and politico-economic environment.

The Trelleborg case shows the three dimensions in relation to the re-conceptualization of a hospital meal. There were plenty of cognitive rules about how a hospital meal should be, that turned out to be an impediment for innovation, sometimes in direct conflict to the normative and strategic dimensions. Furthermore, the regimes of the public staff, the political level and the innovation facilitating actor (SFIN) were difficult to bridge, as shown in the initial conflicts about the hospital kitchen.

The road to successful innovation work turned out to be the combination of people that could function as intermediaries between the different regimes in action. People working for SFIN had credibility among the hospital staff, while the experienced and renowned chef's 
knowledge of food preparation could not be disputed. The SFIN project leader turned out to have unknown skills for intermediating between the outside organisation and the higher administrative and political level.

There is still work to be done before the new paradigm of hospital meals is successfully launched in Trelleborg, especially the implementation at ground level. The innovation is not a success until all levels are imprinted with the mission for change.

\section{Notes on contributors}

Håkan Jönsson, associate professor in European Ethnology is researcher and lecturer at the Department of Arts And Cultural Sciences at Lund University, where he teaches at the Master of Applied Cultural Analysis program (www.maca.ac). He is also head of operations in the Skane Food Innovation Network, responsible for the area of small scale food manufacturers and culinary tourism.

Hans Knutsson is assistant professor at the School of Economics and Management, Lund University. He teaches accounting, management control, and strategy and focuses his research on public management and cluster development. He is head of operations in the Skane Food Innovation Network, running the area of Meal Pleasure/Public Meals.

\section{Author details}

Håkan Jönsson and Hans Knutsson

Lund University, Sweden

\section{References}

[1] Argyris, C, \& Schön, D. (1978). Organizational Learning: A theory of action perspective. Addison-Wesley.

[2] Christensen, C. M. (1997). The innovator's dilemma. When new technologies cause great firms to fail. Harvard Business School Press, Boston.

[3] Christensen, C. M, Baumann, H, Ruggles, R, \& Sadtler, T. M. (2006). Disruptive Innovation for Social Change, Harvard Business Review, December, , 94-101.

[4] Cohen, M. D, Burkhart, R, Dosi, G, Egidi, M, Marengo, L, Warglien, M, \& Winter, S. (2004). Routines and other recurring action patterns of organizations: contemporary research issues, in Dosi et al (2004). 
[5] Dosi, G, Teece, D. J, \& Chytry, J. (2004). Understanding Industrial and Corporate Change, Oxford University Press.

[6] Drucker, P. F. (1994). The Theory of the Business, Harvard Business Review, September, , 95-105.

[7] EdquistCharles and Hommen, Leif ((1999). Systems of innovation: theory and policy for the demand side. Technology In Society, 21, , 63-79.

[8] Edquist, C. (2002). Innovation Policy for Sweden- Objectives, Rationales, Problems and Measures. The Swedish Agency for Innovation Systems, VFI 2002:2.

[9] Ghoshal, S. (2005). Bad management theories are destroying good management practices. Academy of Management Learning \& Education, 4, 1, , 75-91.

[10] Govindarajan, V, \& Trimble, C. (2010). The other side of innovation. Solving the execution challenge. Harvard Business Press, Boston.

[11] Hodgson, G. (1988). Economics and Institutions, Polity Press.

[12] Johnson, S. (2010). Where good ideas come from. The natural history of innovation, Penguin Group, New York.

[13] Jönsson, H, Knutsson, H, \& Frykfors, C-O. (2011). Facilitating Innovations in a Mature Industry-Learnings from the Skane Food Innovation Network, in Valdez (2011).

[14] Lagnevik, M. (2006). Food innovation at interfaces: experience from the Öresund region', in Hulsink, W.; Dons, H. (Eds.) Pathways to High-Tech Valleys and Research Triangles. Wageningen: Wageningen UR Frontis Series, 24.

[15] Levinthal, D. A. (1991). Organizational adaption and environmental selections-interrelated processes of change. Organization Science , 2, 140-45.

[16] Lewin, K. (1946). Action research and minority problems. Journal of Social (2), 34-46.

[17] Miles, R. E, \& Snow, C. C. (1984). Fit, Failure And the Hall of Fame, California Management Review, 26, 3, , 10-29.

[18] Mintzberg, H. (1978). Patterns in Strategy Formation, Management Science, 24, 9, , 934-948.

[19] Moore, G. A. (1991). Crossing the chasm, HarperBusiness.

[20] Normann, R. (1975). Skapande företagsledning, Aldus, Stockholm.

[21] Normann, R. (2001). Reframing Business- When the Map Changes the Landscape, Wiley, London.

[22] OECD ((2012). Territorial Reviews. Skåne, Sweden 2012. OECD Publishing.

[23] Porter, M. E. (1985). Competitive Advantage: Creating and Sustaining Superior Performance, Free Press, New York.

[24] Porter, M. E. (1990). The Competitive Advantage of Nations, Free Press, New York. 
[25] Porter, M. E. (1996). What is strategy?, Harvard Business Review, November-December, , 61-78.

[26] Porter, M. E. (2008). The Five Competitive Forces That Shape Strategy, Harvard Business Review, January, , 79-93.

[27] Rapaport, R. N. (1970). Three dilemmas of action research. Human Relations, 23, in Susman and Evered (1978)., 499-513.

[28] Scott, W. R. (1995). Institutions and Organizations, Sage.

[29] Selznick, P. (1957). Leadership in Administration, Harper \& Row, New York.

[30] Susman, G. I, \& Evered, R. D. (1978). An Assessment of the Scientific Merits of Action Research, Administrative Science Quarterly, 23, 4, , 582-603.

[31] Valdez, B. ed., ((2011). Scientific, Health and Social Aspects of the Food Industry, InTech.

[32] Veblen, T. (1904). The Theory of Business Enterprise, Charles Scribner's Sons. New York.

[33] Winter, S, \& Nelson, R. R. (1982). An Evolutionary Theory of Economic Change, Harvard University Press.

[34] Depree, M. (2004). Leadership is an art, Bantam Dell.

[35] Schein, E. H. (2010). Organizational Culture and Leadership, 4th ed, Jossey-Bass.

[36] Kotter, J. P. (1985). Power and influence,

[37] Kotter, J. P. (1996). Leading change, Harvard Business School Press.

[38] March, J. G. (1991). Exploration and Exploitation in Organizational Learning, Organization Science, 2, 1, , 71-87.

[39] Collins, J. (2001). Good to Great. Why Some Companies Make the Leap... and Others Don't, HarperCollins.

[40] Collins, J, \& Hansen, M. T. (2011). Great by Choice: Uncertainty, Chaos, and LuckWhy some thrive despite them all. HarperCollins. 